\title{
High-glycaemic index and -glycaemic load meals increase the availability of tryptophan in healthy volunteers
}

\author{
Christopher P. Herrera ${ }^{1}+$, Keir Smith ${ }^{2}$, Fiona Atkinson ${ }^{2}$, Patricia Ruell ${ }^{1}$, Chin Moi Chow ${ }^{1}$, \\ Helen O'Connor ${ }^{1}$ and Jennie Brand-Miller ${ }^{2,3}$ \\ ${ }^{1}$ Discipline of Exercise and Sport Science, Faculty of Health Sciences, University of Sydney, Sydney, NSW, Australia \\ ${ }^{2}$ School of Molecular Bioscience, Faculty of Science, University of Sydney, Sydney, NSW, Australia \\ ${ }^{3}$ Boden Institute of Obesity, Nutrition, and Exercise, University of Sydney, Sydney, NSW, Australia
}

(Received 12 July 2010 - Revised 29 October 2010 - Accepted 12 November 2010 - First published online 24 February 2011)

\begin{abstract}
The purpose of the present study was to determine the influence of the glycaemic index (GI) and glycaemic load (GL) on the ratio of tryptophan (TRP) relative to other large neutral amino acids (LNAA). Ten healthy men (age 22.9 (sD $3 \cdot 4$ ) years; BMI $23 \cdot 5$ (sD 1.6 ) kg/m²) underwent standard GI testing, and later consumed each of a mixed-macronutrient (1915 kJ; 66.5\% carbohydrate (CHO), $17 \%$ protein and $16.5 \%$ fat) high-GI (MHGI), an isoenergetic, mixed-macronutrient low-GI (MLGI) and a CHO-only $(3212 \mathrm{~kJ} ; 90 \% \mathrm{CHO}, 8 \%$ protein, $2 \%$ fat) high-GI (CHGI) meal on separate days. The GI, GL and insulin index values (e.g. area under the curve) were largest after the CHGI meal $(117,200,158)$, followed by the MHGI $(79,59,82)$ and MLGI $(51,38,56)$ meals, respectively (all values were significantly different, $P<0 \cdot 05)$. After the MHGI and MLGI meals but not after the CHGI meal, TRP was elevated at 120 and $180 \mathrm{~min}(P<0 \cdot 05)$. After the CHGI, LNAA was lower compared with the MLGI $(P<0 \cdot 05)$; also the rate of decline in LNAA was higher after CHGI compared with MHGI and MLGI (both comparisons $P<0.05)$. The percentage increase from baseline in TRP:LNAA after CHGI (23\%) was only marginally higher than after the MHGI meal $(17 \% ; P=0 \cdot 38)$, but it was threefold and nearly significantly greater than MLGI $(8 \% ; P=0 \cdot 05)$. The present study demonstrates that the postprandial rise in TRP:LNAA was increased by additional CHO ingestion and higher GI. Therefore, the meal GL appears to be an important factor influencing the postprandial TRP:LNAA concentration.
\end{abstract}

Key words: Glycaemic index: Glycaemic load: Tryptophan: Amino acids: Carbohydrate

The availability of dietary tryptophan (TRP) to the brain depends on its concentration relative to other large neutral amino acids (LNAA), which compete for a common transport mechanism across the blood-brain barrier ${ }^{(1)}$. Increased consumption of carbohydrate $(\mathrm{CHO})$ elicits a marked demand in insulin secretion, which enhances peripheral, skeletal muscle uptake of LNAA. However, TRP is largely albumin bound and therefore protected from this absorption ${ }^{(2)}$. Previous studies have shown that the postprandial concentration of TRP:LNAA increases between 20 and 50\% compared with baseline after predominately $\mathrm{CHO}-$ rich meals ${ }^{(3-5)}$. In one study, consumption of a sucrose-based food elicited a larger postprandial increase in TRP:LNAA compared with a raw starch-based food ${ }^{(3)}$. Although the glycaemic index (GI) of the foods was not measured, these authors hypothesised that a high-GI CHO-based meal compared with a low-GI
CHO-based meal would elicit a greater insulin release, and therefore a larger postprandial rise in plasma TRP:LNAA levels ${ }^{(3,6,7)}$.

The proportion of $\mathrm{CHO}$ relative to either protein or fat may similarly influence the TRP:LNAA response after mixed-macronutrient meals. Berry et al. ${ }^{(8)}$ suggested that a meal containing a CHO:protein ratio of approximately 5:1 would neither raise nor lower postprandial LNAA, given that the LNAA-lowering effect of the insulin demand would be offset by the contribution of LNAA provided by the protein source. Since TRP is the least abundant amino acid found in protein, a proteinrich, low-CHO meal lowers TRP:LNAA due to a greater contribution of LNAA relative to TRP in the meal ${ }^{(3)}$. Conversely, the addition of fat to a meal retards gastric emptying ${ }^{(9)}$, and lowers the peak glycaemic and insulin response ${ }^{(10)}$. Thus, increased fat content in a meal may attenuate the postprandial

\footnotetext{
Abbreviations: CHGI, carbohydrate-only high glycaemic index; CHO, carbohydrate; GI, glycaemic index; GL, glycaemic load; LNAA, large neutral amino acids; MHGI, mixed-macronutrient high glycaemic index; MLGI, mixed-macronutrient low glycaemic index; TRP, tryptophan.
}

*Corresponding author: Dr C. P. Herrera, fax +974 4413 2020, email christopher.herrera@aspetar.com

† Present address: Research and Education Centre, ASPETAR - Qatar Orthopaedic and Sports Medicine Hospital, PO Box 29222, Doha, Qatar. 
TRP:LNAA response after mixed-macronutrient meals when compared with a CHO-only meal.

Recently, the GI of a CHO-rich meal has been shown to significantly influence sleep initiation in healthy sleepers. Afaghi et $\mathrm{al}^{(11)}$ reported a $50 \%$ reduction in the time required to fall asleep after a CHO-rich, high-GI meal compared with an isoenergetic low-GI meal when consumed $4 \mathrm{~h}$ before bedtime. This improvement in sleep initiation after a high-GI CHO meal was probably due to an increased plasma TRP:LNAA concentration and increased serotonin; however, biochemical data were not collected to support this claim.

Therefore, the purpose of the present study was to investigate the influence of the GI and glycaemic load (GL) on the TRP:LNAA response after a CHO-only high-GI (CHGI) meal compared with two isoenergetic, mixed-macronutrient highand low-GI (MHGI and MLGI) meals. We hypothesise that the glycaemic and insulin response to the CHGI meal will be larger than the MHGI and MLGI meals, and the corresponding increase in TRP:LNAA will be proportional to the GL of the meals due to differences in insulin demand.

\section{Methods and materials}

\section{Participants}

Ten healthy mixed-ethnicity men (age 22.9 (SD 3.4) years) of normal weight (BMI $23.5(\mathrm{SD} 1.6) \mathrm{kg} / \mathrm{m}^{2}$ ) were recruited from a university student population. Exclusion criteria included a self-reported current or past history of medical, psychiatric or sleep disorder, current use of prescribed medication, recreational drug use, allergy related to the study meals or habitual use of a restrictive diet. The present study was conducted according to the guidelines laid down in the Declaration of Helsinki, and all procedures involving human subjects were approved by the Human Research Ethics Committee of the University of Sydney. Written informed consent was obtained from all subjects before participation.

\section{Meals}

The energy and macronutrient composition of the meals are summarised in Table 1 . The CHGI meal, $3212 \mathrm{~kJ}$, was replicated from a previous study ${ }^{(11)}$ and consisted of a large portion of rice (Jasmine GI approximately 109; Riviana Foods, Sydney, NSW, Australia) served with a tomato-based vegetable purée. The mixed-macronutrient meals (MHGI and MLGI) were isoenergetic, approximately $1915 \mathrm{~kJ}$, and consisted of rice (MHGI: Jasmine GI approximately 109; MLGI: Doongara GI approximately 46; Riviana Foods) served with a sachet of chicken with sun-dried tomato sauce $(965 \mathrm{~kJ}$; $7.9 \mathrm{~g}$ fat, $14.1 \mathrm{~g}$ protein and $24.7 \mathrm{~g} \mathrm{CHO}$;Lean Cuisine ${ }^{\mathrm{TM}}$; Nestlé Australia Limited, Rhodes, NSW, Australia). Meals were prepared in the University of Sydney Human Nutrition Unit kitchens. Uncooked rice (raw weight of CHGI, $200 \mathrm{~g}$; MHGI, $64.7 \mathrm{~g}$; MLGI, $64.5 \mathrm{~g}$ ) was prepared using an electric rice cooker before the testing day, with a rice:water ratio of $1: 1 \cdot 5$. Cooked rice was frozen $\left(-20^{\circ} \mathrm{C}\right)$ in individual portions and reheated in a microwave before serving. Frozen Lean Cui$\operatorname{sine}^{\mathrm{TM}}$ sachets were heated in the microwave according to the manufacturer's recommendations and poured over the rice immediately before serving. All meals were presented to the participants with $250 \mathrm{ml}$ of cool water and consumed within 15 min. Participants were required to consume the entire meal, which was assessed visually by a researcher (C. P. H. and K. S.) and by weighing the plate before and after eating.

\section{Procedure}

Participants presented to the testing facility in the morning by at least 10.00 hours, having fasted overnight for a period of at least $8 \mathrm{~h}$. Participants were required to avoid vigorous exercise and abstain from alcohol for at least $24 \mathrm{~h}$ before testing, and were instructed to avoid over- or under-eating. Smokers were instructed to abstain on the morning before testing. On the night before testing, participants were instructed to consume a high-CHO, low-fat evening meal devoid of legumes in order to avoid extreme hunger and variation in basal blood glucose concentration. Self-reported compliance with these instructions was evaluated by a researcher (C. P. H. and K. S.) each morning before testing.

Participants initially completed three independent reference glucose tests separated by at least $48 \mathrm{~h}$ apart. Each reference test used a standard glucose drink $\left(77 \cdot 1 \mathrm{~g}\right.$ Glucodin $^{\mathrm{TM}}$ powder, dissolved in $250 \mathrm{~g}$ of cold water), providing $75 \mathrm{~g}$ available $\mathrm{CHO}$, in order to calculate the average glucose and insulin response. A glucose load of $75 \mathrm{~g}$ was required to appropriately determine the GI of the MHGI and MLGI meals ${ }^{(12)}$; however, the GI of the CHGI meal would be approximate as it was considered unethical to use a glucose

Table 1. Energy and macronutrient composition of the carbohydrate ( $\mathrm{CHO}$ ) high-glycaemic index (CHGI), mixed-macronutrient high-glycaemic index (MHGI) and mixed-macronutrient low-glycaemic index (MLGl) meals

\begin{tabular}{|c|c|c|c|c|c|c|c|c|c|}
\hline \multirow[b]{2}{*}{ Meal } & \multirow[b]{2}{*}{ Energy (kJ) } & \multicolumn{2}{|r|}{ Fat } & \multicolumn{2}{|c|}{ Protein } & \multicolumn{2}{|c|}{$\mathrm{CHO}$} & \multirow[b]{2}{*}{$\mathrm{Gl}^{*}$} & \multirow[b]{2}{*}{$\mathrm{GL} \dagger$} \\
\hline & & $\mathrm{g}$ & Energy (\%) & $g$ & Energy (\%) & g & Energy (\%) & & \\
\hline CHGl & 3212 & 0.4 & 1.6 & $16 \cdot 8$ & 8 & 171.4 & 90.4 & 117 & 200 \\
\hline MHGI & 1916 & 7.9 & $16 \cdot 2$ & 18.2 & $17 \cdot 2$ & 75 & $66 \cdot 6$ & 79 & 59 \\
\hline MLGI & 1913 & 7.9 & $16 \cdot 1$ & 18.6 & 17.5 & 75 & 66.4 & 51 & 38 \\
\hline
\end{tabular}

Gl, glycaemic index; GL, glycaemic load.

* Gl was determined using the average glucose response $(n 9)$ and the incremental area under the curve method $\left.{ }^{(12)}\right)$.

$\dagger \mathrm{GL}$ was calculated by multiplying each meal $\mathrm{Gl}$ by the available $\mathrm{CHO}(\mathrm{g})$.

$\ddagger \mathrm{Gl}$ for the $\mathrm{CHGl}$ meal was approximate due to a larger $\mathrm{CHO}$ content of this test meal compared with the reference glucose drink providing $75 \mathrm{~g} \mathrm{CHO}^{(12)}$. 
reference drink of $171.4 \mathrm{~g}$ CHO. All meals were administered in a randomised order at least $48 \mathrm{~h}$ apart. Participants were blinded to the GI of the MHGI and MLGI meals, which were identical in appearance. A questionnaire comprising multiple, $10 \mathrm{~cm}$ visual analogue scales was administered immediately after meal consumption to assess palatability ( 0 , poor; 10 , good), satiety (0, still hungry; 10 , completely full) and participant sleepiness ( 0 , alert; 10 , sleepy). The validity of visual analogue scales to assess subjective ratings of palatability and mood states after meal consumption is well established ${ }^{(13,14)}$.

\section{Calculation of glycaemic index, insulin index and glycaemic load}

GI and insulin index were calculated according to published guidelines using mean participant data and the following ratio: the 120 min incremental area under the curve of the test meal compared with the mean incremental area under the curve of the reference food, multiplied by $100^{(12)}$. GL was calculated using the equation, $\mathrm{GL}=(\mathrm{GI} / 100) \times \mathrm{g}$ available $\mathrm{CHO}^{(15)}$. It can be highlighted again that despite identical macronutrient and energy composition, the MHGI and MLGI meals were designed to elicit differences in postprandial GL response. This was accomplished by the selection of either a $75 \mathrm{~g}$ portion of a high-GI (109) rice for the MHGI meal or a $75 \mathrm{~g}$ portion of a low-GI (49) rice for the MLGI meal (see meals above). Thus, the overall glycaemic response of these meals will reflect not only the amount and type of $\mathrm{CHO}$, but also the relative contributions of the fat and protein components ${ }^{(9)}$. This meal design illustrates the importance of investigating the GI of an entire mixed-macronutrient meal ${ }^{(16)}$.

\section{Biochemical analysis}

Finger-prick blood samples were collected into separate heparin-coated eppendorf tubes at baseline $(5$ and $1 \mathrm{~min}$ before meal consumption) and after 15, 30, 45, 60, 90 and $120 \mathrm{~min}$ for the analysis of glucose (glucose hexokinase enzymatic assay, Hitachi 912 automatic analyser; Boehringer, Mannheim, Germany) and insulin (solid-phase antibodycoated tube RIA, 'Coat-A-Count' Insulin RIA kit; Diagnostic Products Corporation, Los Angeles, CA, USA). All samples were immediately centrifuged at $7900 \mathrm{rpm}$ for $45 \mathrm{~s}$, with plasma stored at $-20^{\circ} \mathrm{C}$ for the subsequent analysis.

After test meals but not after reference tests, additional ( $2 \mathrm{ml}$ ) blood samples were collected by venepuncture from a forearm vein into a Li-heparinised tube at 0 (baseline), 120, 180 and $240 \mathrm{~min}$, and immediately centrifuged (2500 rpm for $15 \mathrm{~min}$ at $4^{\circ} \mathrm{C}$ ) to separate plasma for subsequent analysis of amino acids: TRP and five LNAA (valine, leucine, isoleucine, phenylalanine and tyrosine) to calculate the TRP:LNAA ratio ${ }^{(2)}$. Plasma samples were collected into separate eppendorf tubes and stored at $-80^{\circ} \mathrm{C}$ until analysis of amino acids by reverse-phase HPLC (Shimadzu, Kyoto, Japan). All samples were analysed in duplicate following established methodology ${ }^{(17)}$.

\section{Statistics}

Data are reported as means and standard deviations. All data were tested for normality of distribution, and statistical procedures were completed using SPSS for Windows (SPSS version 15.0, Inc.; Cary, NC, USA). Student's paired-sample $t$ tests were used to identify differences between the meals in palatability, satiety, sleepiness (visual analogue scales), the GI, GL, insulin index and the incremental area under the curve of the TRP:LNAA response. A two-factor (meal $\times$ time), repeated-measures ANOVA was used to test for the postprandial effect of time, meal type and their interaction on TRP, LNAA and TRP:LNAA concentrations. In ANOVA, normality was satisfied using Mauchly's test of sphericity unless reported with the Greenhouse-Geisser value. Significance was set at $P<0 \cdot 05$.

\section{Results}

Palatability, satiety and sleepiness (visual analogue scales)

Palatability of the MHGI and MLGI meals was identical and indicated a 'good taste'; both mean positive scores were 8.3 (sD 1.4) $\mathrm{cm} ; P=0.956$. Both MHGI and MLGI meals were significantly more palatable than the CHGI meal (3.2 (sD $2 \cdot 2) \mathrm{cm}$; both comparisons $P<0 \cdot 001)$. Satiety was slightly and almost significantly $(P=0.05)$ higher after the MHGI meal $(6.2(\mathrm{SD} 1.6) \mathrm{cm})$ compared with the MLGI meal (4.9) (SD 2.4) $\mathrm{cm})$. Both these ratings were significantly lower than the CHGI meal (8.7 (SD 1.1) cm; $P<0.001)$. There were no significant differences between subjective ratings for sleepiness (CHGI $6.2(\mathrm{sD} 1.7) \mathrm{cm}$, MHGI 5.6 (SD 1.9) cm, MLGI 4.8 (sD $2 \cdot 4) \mathrm{cm} ; P>0.05)$.

\section{Glycaemic index, glycaemic load and insulin index}

Postprandial concentrations for blood glucose and insulin are shown in Fig. 1. Data were omitted from one participant due to an abnormal fasting glucose concentration ${ }^{(12)}$. The GI, GL and insulin index values were all significantly different between the meals (all $P<0.05$ ). The estimated GI for the CHGI (116.6 (SD 30.1)) meal and exact value for the MHGI (78.6 (SD 17.8)) meal were in the high $(\mathrm{GI} \geq 70)$ range, whereas the GI for the MLGI (50.8 (SD 20.4)) meal was in the low range $(\mathrm{GI} \leq 55)^{(18)}$. Calculated GL values were greatest after the CHGI (200) meal, followed by the MHGI (58.9) and MLGI (38.2) meals. Insulin index was greatest after the CHGI (158 (SD 59.9)) meal, followed by the MHGI (81.9 (SD 37.2)) and MLGI (55.7 (SD 25.6)) meals, respectively.

\section{Amino acid concentrations}

Postprandial TRP and LNAA concentrations are presented in Table 2. Data were from seven participants; two participants failed to complete all venepuncture procedures. All basal amino acid concentrations were not statistically different between the meals.

TRP after the MHGI and MLGI meals was elevated compared with baseline at $120 \quad(P=0.02)$ and $180 \mathrm{~min}$ 


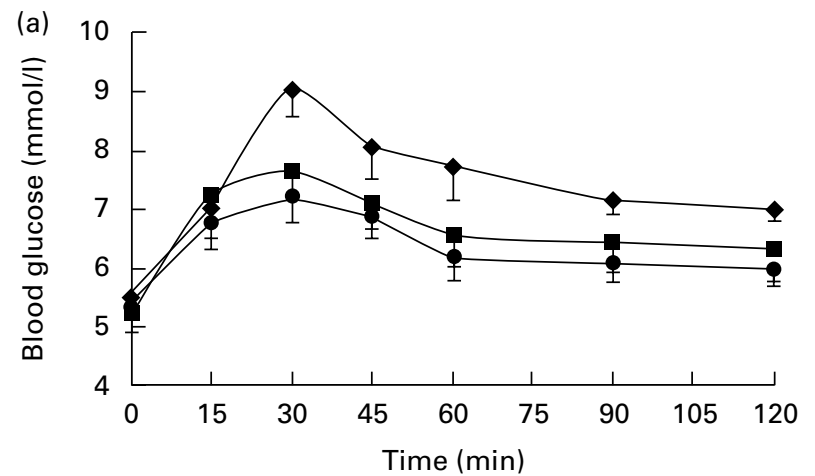

(b)

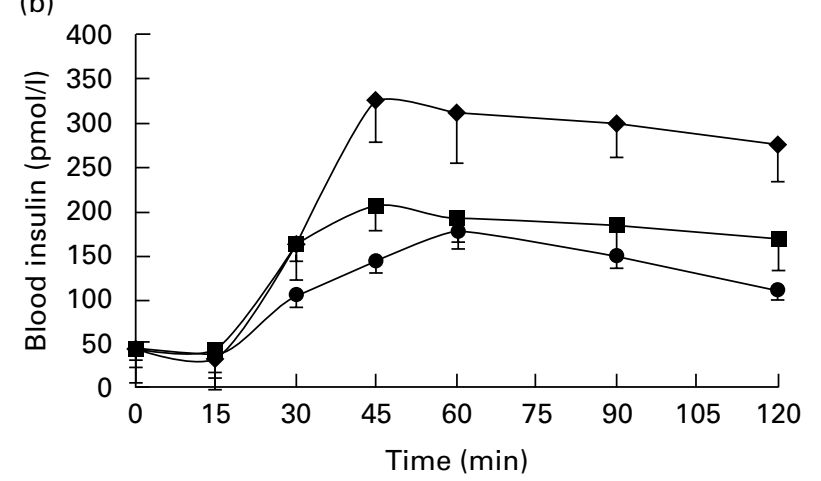

Fig. 1. Postprandial (a) glucose and (b) insulin responses after the carbohydrate-only high-glycaemic index (CHGI), mixed-macronutrient highglycaemic index (MHGl) and mixed-macronutrient low-glycaemic index (MLGI) meals in healthy participants. Postprandial glucose was maximal at $30 \mathrm{~min}$ in all meal conditions before steadily declining to concentrations slightly above baseline at $120 \mathrm{~min}$. Postprandial insulin peaked at approximately $45 \mathrm{~min}$ after the $\mathrm{CHGl}$ and MHGI meals but at approximately $60 \mathrm{~min}$ after the MLGI meal followed by a gradual reduction. The incremental area under the curve data indicate that the glycaemic index (GI), glycaemic load and insulin index values were largest after the CHGI $(117,200,158)$ meal, followed by the MHGI $(79,59,82)$ and $\operatorname{MLGI}(51,38,56)$ meals, respectively. Values were significantly different $(P<0.05)$., $\mathrm{CHGl}$; $\mathbf{M H G l} \bullet \bullet, \mathrm{MLGl}$.

$(P<0.001)$, but declined to levels similar to baseline at 240 min. Conversely, there was a marginal postprandial decline in TRP after the CHGI meal (time; $F(1 \cdot 2,7 \cdot 4)=7 \cdot 2, P=0.026$ (Greenhouse-Geisser)); however, no significant change was observed from baseline ( $P>0 \cdot 05)$.

After the MLGI meal, LNAA was initially increased at 120 min $(P=0.03)$ and then declined, whereas after both the MHGI and MLGI meals, there was a significant postprandial decline in LNAA (time; $F(3,18)=43.2, P<0.001$ ). The rate of change was significantly different between the meals (meal $\times$ time; $F(6,36)=8.7, P<0.01)$; the decline in LNAA after the CHGI meal was more rapid than after the MLGI $(P=0.001)$ and MHGI $(P=0.004)$ meals. In addition, the total decline in LNAA after the CHGI meal was significantly greater than after the MLGI $(P=0 \cdot 04)$ meal but not after the MHGI $(P=0 \cdot 10)$ meal.

The postprandial TRP:LNAA response is shown in Fig. 2. Basal TRP:LNAA was not significantly different between the meals. TRP:LNAA increased with time after all meals (time; $F(1 \cdot 7,10)=17 \cdot 3, P=0 \cdot 001$ (Greenhouse-Geisser)); the corresponding percentage rise from baseline was approximately 23\% (CHGI), 17\% (MHGI) and 8\% (MLGI). The incremental area under the curve was greatest after the CHGI (4.4 (SD 2.6)) meal, followed by the MHGI (2.8 (SD 3.7)) and MLGI (1.4 (SD 1.4)) meals; these values were not statistically significant between the CHGI and MHGI meals $(P=0.38)$ meals or between the MHGI and MLGI meals ( $P=0 \cdot 43$ ); however, there was a trend present between the CHGI and MLGI ( $P=0.05)$ meals, and the one-tailed $t$ test was significant $(P=0.03)$.

\section{Discussion}

The present study examined the influence of the GI and GL on the postprandial concentration of TRP:LNAA. The study results indicate that the MHGI and MLGI meals resulted in a lower glycaemic and insulin response compared with the CHGI meal. In addition, there was an initial increase in TRP after the MHGI and MLGI meals, whereas after the CHGI meal, changes in TRP were unremarkable. Conversely, the rate of decline in LNAA was markedly higher after the CHGI meal compared with the MHGI and MLGI meals. As a result, there was a substantial postprandial rise in TRP:LNAA after the CHGI meal, which was slightly attenuated after the MHGI meal, and relatively small after the MLGI meal.

The decrease in the glycaemic and insulin response of the MHGI and MLGI meals confirms our initial hypothesis and demonstrates substantial clinical improvement compared to the CHGI meal. The GL of the MHGI (GL 59) and MLGI (GL 38) was significantly lower than the CHGI meal (GL 200). Epidemiological studies have linked high-GI and -GL diets to increased risk of CVD and for the development of type 2 diabetes $^{(19,20)}$. A GL value of $>120$ over a single day is regarded

Table 2. Mean postprandial tryptophan (TRP) and large neutral amino acid (LNAA) concentrations and TRP:LNAA ratio after the carbohydrate-only high-glycaemic index (CHGI), mixed-macronutrient highglycaemic index (MHGl) and mixed-macronutrient low-glycaemic index (MLGI) meals in healthy participants $(n 7)$

(Mean values and standard deviations)

\begin{tabular}{|c|c|c|c|c|c|c|}
\hline \multirow[b]{2}{*}{ Meals } & \multicolumn{2}{|c|}{$\begin{array}{c}\text { TRP } \\
(\mu \mathrm{mol} / \mathrm{l})\end{array}$} & \multicolumn{2}{|c|}{$\begin{array}{l}\text { LNAA }^{*} \\
(\mu \mathrm{mol} / \mathrm{l})\end{array}$} & \multicolumn{2}{|c|}{ TRP:LNAA } \\
\hline & Mean & SD & Mean & SD & Mean & SD \\
\hline \multicolumn{7}{|l|}{ CHGI† } \\
\hline $0 \mathrm{~min}$ & 64 & 9 & 593 & 65 & 0.1077 & 0.014 \\
\hline $120 \mathrm{~min}$ & 63 & 8 & $480 \ddagger$ & 36 & $0.1328 \ddagger$ & 0.022 \\
\hline $180 \mathrm{~min}$ & 61 & 9 & $468 \ddagger$ & 47 & $0.1308 \ddagger$ & 0.020 \\
\hline $240 \mathrm{~min}$ & 58 & 7 & $439 \ddagger$ & 35 & $0.1326 \ddagger$ & 0.018 \\
\hline \multicolumn{7}{|l|}{ MHGI } \\
\hline $0 \mathrm{~min}$ & 59 & 7 & 559 & 68 & 0.1075 & 0.022 \\
\hline $120 \mathrm{~min}$ & $67 \ddagger$ & 11 & 558 & 53 & $0.1215 \ddagger$ & 0.020 \\
\hline $180 \mathrm{~min}$ & $65 \ddagger$ & 11 & $528 \ddagger$ & 52 & $0.1235 \ddagger$ & 0.020 \\
\hline $240 \min$ & 61 & 9 & $516 \ddagger$ & 54 & $0.1198 \ddagger$ & 0.019 \\
\hline \multicolumn{7}{|l|}{ MLGI† } \\
\hline $0 \mathrm{~min}$ & 66 & 5 & 560 & 47 & 0.1179 & 0.009 \\
\hline $120 \mathrm{~min}$ & $73 \ddagger$ & 9 & $591 \ddagger$ & 53 & 0.1233 & 0.016 \\
\hline $180 \mathrm{~min}$ & $70 \ddagger$ & 7 & 554 & 39 & $0.1269 \ddagger$ & 0.015 \\
\hline $240 \mathrm{~min}$ & 63 & 6 & $501 \ddagger$ & 52 & $0.1255 \ddagger$ & 0.012 \\
\hline
\end{tabular}

* LNAA: valine, isoleucine, leucine, phenylalanine and tyrosine.

$\dagger$ Incremental area under the curve was significantly greater after the CHGI meal compared with the MLGI meal (two-tailed $t$ test, $P=0.054$; one-tailed $t$ test, $P=0.03)$.

$\ddagger$ Mean values were statistically significant compared with baseline $(P<0.05)$. 


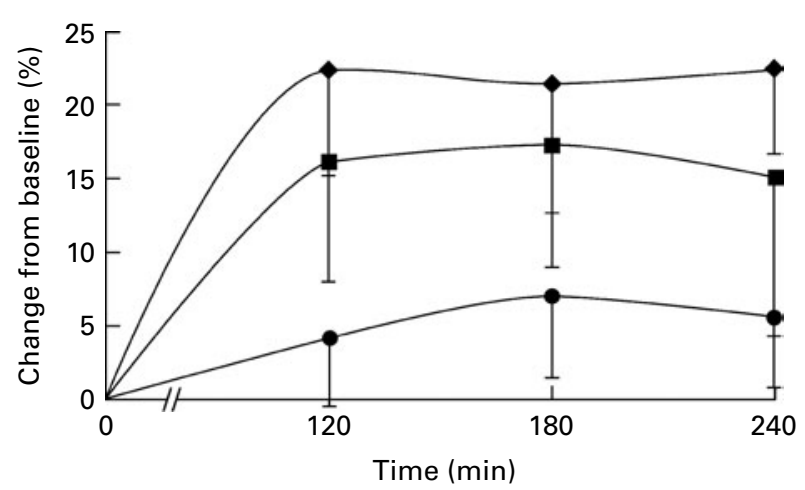

Fig. 2. Effects of the carbohydrate-only high-glycaemic index (CHGI), mixedmacronutrient high-glycaemic index (MHGI) and mixed macronutrient low glycaemic index (MLGI) meals on postprandial tryptophan (TRP)/large neutral amino acid (LNAA) concentrations in healthy participants. There was a significant postprandial rise after each meal with a peak percentage increase between 180 and 240 min after meal consumption. The corresponding peak percentage rise was approximately 23,17 and $8 \%$ after the CHGI, MHGI and MLGI meals, respectively. The incremental area under the curve data indicate that TRP:LNAA levels after the $\mathrm{CHGI}$ meal were greater than after the MLGI meal (two-tailed $t$ test, $P=0.054$; one-tailed $t$ test, $P=0.03$ ). $\bullet, \mathrm{CHGl} ; \mathbf{\square}, \mathrm{MHGl} ; \bullet, \mathrm{MLGl}$

as high $^{(21)}$. Hence, this study confirms that the GL of the CHGI meal was over 1.5 times greater than what is clinically recommended for an entire day ${ }^{(11)}$. Conversely, given regular consumption of the MHGI or MLGI as an evening meal, the cumulative daily GL could be kept below high levels. In addition, the MHGI and MLGI meals were similar in taste, had higher palatability ratings and were approximately $50 \%$ less in energy relative to the CHGI meal (Table 1). Moreover, the mixed-macronutrient profile of the MHGI and MLGI meals is consistent with Western dietary guidelines ${ }^{(22,23)}$. Thus, it is likely that these meals would be easily accepted as part of a regular diet in future studies.

The biochemical results of the study suggest that a simple manipulation of the amount and type of $\mathrm{CHO}$ in a single meal can lead to a substantial change in postprandial amino acid concentration. Given that the macronutrient composition of the MHGI and MLGI meals was identical and each contained the same protein source (e.g. chicken breast sachet), it is likely that these meals contributed an identical amount of dietary TRP, and that this amount was greater than the CHGI meal, which comprised mainly rice and vegetables ${ }^{(24)}$. Indeed, there was a significant increase in TRP concentration at 120 and 180 min after the MHGI and MLGI meals but not after the CHGI meal (Table 2). Conversely, there was an overall decline from baseline in LNAA at the end of the study period after all meals (240 min; Table 2 ), and a higher rate of change in LNAA after the CHGI meal compared with the MHGI and MLGI meals. These findings together suggest that the postprandial decline in LNAA was largely dependent on the type (high-GI $v$. low-GI rice) and amount of $\mathrm{CHO}(75 \mathrm{~g}$ in the mixed-macronutrient meals $v .171 \mathrm{~g}$ in CHGI meal) in the meals (Table 1). Furthermore, the decline in LNAA presented after the MHGI and MLGI meals indicates that a CHO: protein ratio of approximately $4: 1$ results in a significant uptake of LNAA into skeletal muscle. Thus, the present study suggests that the postprandial change in LNAA is largely dependent on the meal GL and not on the ratio of CHO:protein, as suggested earlier to be responsible for the change in LNAA $^{(8)}$.

The present data further indicate that the increase in postprandial TRP:LNAA was inversely proportional to the magnitude and rate of decline in LNAA. In fact, the TRP:LNAA response after the CHGI meal is in line with those from previous studies ${ }^{(3-5)}$. Importantly, the postprandial concentration of TRP:LNAA dictates the synthesis of central nervous system serotonin $^{(25)}$, a key neurotransmitter involved in the regulation of sleep ${ }^{(26)}$. In a separate study, the CHGI meal was previously shown to improve sleep initiation when provided $4 \mathrm{~h}$ before bedtime compared with an isoenergetic low-GI version ${ }^{(11)}$. Furthermore, Blum et al. reported that the consumption of a similar-sized CHO breakfast meal resulted in a $461 \%$ increase from baseline in the postprandial insulin response and a 3.5fold increase in platelet poor plasma serotonin in healthy subjects ${ }^{(27)}$. Thus, the peak percentage change from baseline in insulin after the CHGI meal (650\%) indicates that postprandial serotonin was probably increased, which may therefore explain the improvement in sleep initiation after the CHGI meal $^{(11)}$. In addition, given the peak insulin response to the MHGI meal (450\%), it remains a possibility that such a mixed-macronutrient meal may similarly improve sleep initiation $^{(4,28)}$. However, given the reduced TRP:LNAA response, we may speculate that this improvement would be present only when sleep propensity is high, such as in the post-lunch period or in the late evening ${ }^{(29-31)}$.

There are several limitations with the present study. It was difficult to estimate $a$ priori the sample size required to identify meal difference in amino acid concentration due to a limited number of published data using mixed-macronutrient meals. Future studies should inflate sample size estimates, which will also help to account for common difficulties with venepuncture. Moreover, since the study was conducted in the morning and the room was abundant with natural light, postprandial serotonin was not measured due to the risk of platelet contamination ${ }^{(32)}$. Indeed, inadequate satiety and low levels of serotonin are linked to clinical disorders such as insomnia ${ }^{(33)}$, seasonal affective disorder or severe premenstrual syndrome ${ }^{(34)}$. However, since the participants in the present study were all healthy, young, male adults, it is unknown how these results would generalise to such clinical groups, or women and older participants.

In summary, the present study demonstrates that the postprandial TRP:LNAA response to a mixed-macronutrient and a CHO-only meal was increased by higher $\mathrm{CHO}$ ingestion and higher GI. Therefore, the meal GL appears to be an important factor influencing the postprandial TRP:LNAA response. These findings may have clinical relevance for management of conditions where increased serotonin production is considered beneficial, primarily for promotion of sleep in patients with insomnia ${ }^{(35,36)}$. Specific research would be required to assess the risk-benefit of using high-GI meals to promote sleep against current strategies for clinical management of insomnia. 


\section{Acknowledgements}

The present study was supported by a generous supply of rice from Riviana Foods, and meal sachets from Gippsland Food Company, a division of Simplot Australia, Private Limited in cooperation with Nestle Australia. We would like to acknowledge Karola Stockmann from the Sydney University Glycemic Index Research Services group for assisting with the testing in the Human Nutrition Unit kitchens. No author had any financial or other conflicts of interest in the organisation supporting the present study. All authors contributed to the design of the study and test meals. C. P. H. and K. S. implemented the study protocol and completed the collection of data and statistical analysis. C. P. H., K. S., F. A. and P. R. performed the biochemical analysis. C. P. H. and K. S. wrote the manuscript, with C. M. C., H. O'. C. and J. B.-M. involved in data interpretation and editing.

\section{References}

1. Wurtman RJ, Hefti F \& Melamed E (1981) Precursor control of neurotransmitter synthesis. Pharmacol Rev 32, 315-335.

2. McMenamy R \& Oncley JL (1958) The specific binding of 1-tryptophan to serum albumin. J Biol Chem 233, 1436-1447.

3. Lyons PM \& Truswell AS (1988) Serotonin precursor influenced by type of carbohydrate meal in healthy adults. Am J Clin Nutr 47, 433-439.

4. Wurtman RJ, Wurtman JJ, Regan MM, et al. (2003) Effects of normal meals rich in carbohydrates or proteins on plasma tryptophan and tyrosine ratios. Am J Clin Nutr 77, 128-132.

5. Lieberman HR, Caballero B \& Finer N (1986) The composition of lunch determines afternoon plasma tryptophan ratio in humans. J Neural Transm 65, 211-217.

6. Fernstrom JD \& Wurtman RJ (1971) Brain serotonin content: increase following ingestion of carbohydrate diet. Science 174, 1023-1025.

7. Wurtman RJ (1988) Effects of their nutrient precursors on the synthesis and release of serotonin, the catecholamines, and acetylcholine: implications for behavioral disorders. Clin Neuropharmacol 11, Suppl. 1, S187-S193.

8. Berry EM, Growdon JH, Wurtman JJ, et al. (1991) A balanced carbohydrate: protein diet in the management of Parkinson's disease. Neurology 41, 1295-1297.

9. Wells AS \& Read NW (1995) Influences of dietary and intraduodenal lipid on alertness, mood, and sustained concentration. Br J Nutr 74, 115-123.

10. Ercan N, Gannon MC \& Nuttall FQ (1994) Effect of added fat on the plasma glucose and insulin response to ingested potato given in various combinations as two meals in normal individuals. Diabetes Care 17, 1453-1459.

11. Afaghi A, O'Connor H \& Chow CM (2007) High-glycemicindex carbohydrate meals shorten sleep onset. Am J Clin Nutr 85, 426-430.

12. Brouns F, Bjorck I, Frayn KN, et al. (2005) Glycaemic index methodology. Nutr Res Rev 18, 145-171.

13. Flint A, Raben A, Blundell JE, et al. (2000) Reproducibility, power and validity of visual analogue scales in assessment of appetite sensations in single test meal studies. Int $J$ Obes (Lond) 24, 38-48.

14. Rahemtulla Z, Baldwin C, Spiro A, et al. (2005) The palatability of milk-based and non-milk-based nutritional supplements in gastrointestinal cancer and the effect of chemotherapy. Clin Nutr 24, 1029-1037.
15. Brand-Miller JC, Thomas M, Swan V, et al. (2003) Physiological validation of the concept of glycemic load in lean young adults. $J$ Nutr 133, 2728-2732.

16. Henry CJ, Lightowler HJ, Kendall FL, et al. (2006) The impact of the addition of toppings/fillings on the glycaemic response to commonly consumed carbohydrate foods. Eur J Clin Nutr 60, 763-769.

17. Huq F, Thompson M \& Ruell P (1993) Changes in serum amino acid concentrations during prolonged endurance running. Jpn J Physiol 43, 797-807.

18. Foster-Powell K, Holt SH \& Brand-Miller JC (2002) International table of glycemic index and glycemic load. Am J Clin Nutr 76, 5-56.

19. Pawlak DB, Ebbeling CB \& Ludwig DS (2002) Should obese patients be counselled to follow a low-glycaemic index diet? Yes. Obes Rev 3, 235-243.

20. Jenkins DJA, Kendall CWC, Axelsen M, et al. (2000) Viscous and nonviscous fibres, nonabsorbable and low glycaemic index carbohydrates, blood lipids and coronary heart disease. Curr Opin Lipidol 11, 49-56.

21. Brand-Miller J (2009) Home of the glycemic index and glycemic load www.glycemicindex.com (updated 2009; cited December 2009).

22. America USo (2005) Dietary guidelines for Americans, 6th ed. [Services $\mathrm{HaH}$, Agriculture, editor]. Washington, DC: US Government Printing Office.

23. Australia Co (2003) Dietary Guidelines for Australian Adults [NHMRC, editor]. Canberra: AusInfo.

24. Harada T, Hirotani M, Maeda M, et al. (2007) Correlation between breakfast tryptophan content and morningnesseveningness in Japanese infants and students aged 0-15 yrs. J Physiol Anthropol 26, 201-207.

25. Spring B (1984) Recent research on the behavioral effects of tryptophan and carbohydrate. Nutr Health 3, 55-67.

26. Siegel JM (2004) The neurotransmitters of sleep. J Clin Psychiatry 65, 4-7.

27. Blum I, Vered Y, Graff E, et al. (1992) The influence of meal composition on plasma serotonin and norepinephrine concentration. Metabolism 41, 137-140.

28. Orosco M \& Gerozissis K (2001) Macronutrient-induced cascade of events leading to parallel changes in hypothalamic serotonin and insulin. Neurosci Behav Rev 25, 167-174.

29. Dijk DJ \& Cajochen C (1997) Melatonin and the circadian regulation of sleep initiation, consolidation, structure, and sleep EEG. J Biol Rhythms 12, 627-635.

30. Monk TH (2005) The post-lunch dip in performance. Clin Sports Med 24, e15-e23.

31. Wells A, Read N, Idzikowski C, et al. (1998) Effects of meals on objective and subjective measures of daytime sleepiness. J Appl Physiol 84, 507-515.

32. Maria TM, Ribeiro CAF \& Tice RAM (2004) Influence of the sample preparation method on the serotonin determination in plasma and platelets. Biomed Chromatogr 18, 739-744.

33. Bucci L (1988) Migraine, insomnia and reactive depression due to brain-serotonin deficiency. Br J Psychiatry 152, $867-868$.

34. Wurtman RJ \& Wurtman JJ (1995) Brain serotonin, carbohydrate-craving, obesity and depression. Obes Res 3, Suppl. 4, 477S-480S

35. Hartmann E \& Elion R (1977) The insomnia of 'sleeping in a strange place': effect of L-tryptophan. Psychopharmacology 53, $131-133$.

36. Lacey JH, Stanley P, Hartmann M, et al. (1978) The immediate effects of intravenous specific nutrients on EEG sleep. Electroencephalogr Clin Neurophysiol 44, 275-280. 